\title{
Mobile Flowering Locus T RNA - Biological Relevance and Biotechnological Potential
}

\author{
Zhiming Yu ${ }^{1 \star t}$, Weiwei Chen ${ }^{1+}$, Yue Wang ${ }^{1}$, Pengcheng Zhang ${ }^{1}$, Nongnong Shi ${ }^{1}$ and \\ Yiguo Hong 1,2,3*
}

${ }^{1}$ Research Centre for Plant RNA Signaling, College of Life and Environmental Sciences, Hangzhou Normal University, Hangzhou, China, ${ }^{2}$ School of Science and the Environment, University of Worcester, Worcester, United Kingdom, ${ }^{3}$ School of Life Sciences, University of Warwick, Coventry, United Kingdom

\section{OPEN ACCESS}

Edited by:

Xutong Wang,

Purdue University, United States

Reviewed by:

Matthew R. Willmann,

Pairwise, United States

Tien-Shin Yu,

Institute of Plant and Microbial

Biology, Academia Sinica, Taiwan

*Correspondence:

Zhiming Yu

yuzhiming@hznu.edu.cn

Yiguo Hong

yiguo.hong@hznu.edu.cn;

yiguo.hong@warwick.ac.uk;

y.hong@worc.ac.uk

${ }^{t}$ These authors have contributed equally to this work

Specialty section:

This article was submitted to Plant Physiology,

a section of the journal

Frontiers in Plant Science

Received: 09 October 2021

Accepted: 09 December 2021

Published: 03 January 2022

Citation:

Yu Z, Chen W, Wang Y, Zhang P,

Shi N and Hong Y (2022) Mobile

Flowering Locus TRNA - Biological

Relevance and Biotechnological

Potential.

Front. Plant Sci. 12:792192. doi: 10.3389/fp/s.2021.792192
Many systemically mobile mRNAs have been revealed in phloem. However, very few of them have been found to be of clear signaling functions. One of such rare examples is the mobile Flowering locus $T(F T)$ mRNA despite the continuous debate about its mobility and biological relevance to the control of flowering time in plants. Nevertheless, accumulating evidence supports the notion of the long-distance movement of $F T$ mRNA from leaf to shoot apex meristem and its role in flowering. In this review, we discuss the discovery of florigenic $F T$, the initial debate on long-distance movement of $F T$ mRNA, emerging evidence to prove its mobility, and the use of mobile $F T$ mRNA to generate heritable transgenerational gene editing in plants. We elaborate on evidence from virusbased RNA mobility assay, plant grafting, RNA with fluorescent protein labeling, and CRISPR/Cas9 gene-editing technology, to demonstrate that the FT mRNA besides the FT protein can move systemically and function as an integral component of the florigenic signal in flowering. We also propose a model to prompt further research on the molecular mechanism underlying the long-distance movement of this important mobile signaling RNA in plants.

Keywords: florigen, Flowering Locus T, mRNA, long-distancing movement, mobile RNA-based genome editing

\section{INTRODUCTION}

Wheat, rice, and maize are the three most important crops which produce seeds as food to feed people globally (Borlaug, 2002). To produce seeds, flowering is a necessary and significant transition from vegetative to reproductive growth in these crop plants (Srikanth and Schmid, 2011). Therefore, flowering is essential not only for plant propagation but also for the survival of humanity. On the other hand, unlike animals, plants rooting in soil cannot move away from surrounding environments and hazards such as biotic or abiotic stresses. To survive and thrive, plants can generate a wide range of responsive signals. Indeed, stress stimulation sensed, and signals perceived by any part of plants can be collected and transported to cells and/or the entire plant through the vascular system (Takahashi and Shinozaki, 2019). The flowering plant vascular system consists of phloem and xylem, where phloem moves materials in a source-to-sink direction, and xylem typically moves materials upward from the roots, to facilitate transportation of these stimulus signals in plants (Deeken et al., 2008; Lucas et al., 2013). Recently, more and more systemically mobile mRNAs have been revealed in phloem. However, up to now, only a few mRNAs with the 
long-distance movement have been demonstrated to be involved in signal transduction in plant physiological processes (Jackson and Hong, 2012).

To flower, plants perceive the day-length changes in leaves and synthesize a flowering messenger. This signal molecule, dubbed florigen, a theoretical flowering initiation switch, moves long-distance from leave to shoot apical meristem (SAM) through the phloem vascular system to induce flowering (Chailakhyan, 1968; Yanovsky and Kay, 2003; Andrés and Coupland, 2012). However, it took decades to define the nature of florigen, the flowering signaling molecule (Imaizumi and Kay, 2006). In this article, we have discussed the discovery of florigenic Flowering Locus $T(F T)$, the initial debate on long-distance movement of FT mRNA and its biological relevance to flowering, emerging evidence to prove FT mRNA mobility, and the application of mobile FT mRNA to generate heritable transgenerational gene editing. We also discuss ideas to prompt further investigation into the molecular mechanisms underlying the long-distance movement of this important mobile signaling RNA in plants.

\section{ROLE OF FLORIGENIC FLOWERING LOCUS T IN THE INDUCTION OF FLOWERING}

Flowering Locus $T$ encodes mobile florigen to induce plant flowering (Evans, 1971; Turck et al., 2008). This is well documented in literature. For instance, an activation tagged T-DNA mutant overexpressed FT and flowered early independently of day-length (Kardailsky et al., 1999). Ethyl methane sulfonate-induced point mutations in FT such as a single amino acid substitution in $\mathrm{ft}-3$ ( $\operatorname{Arg}_{119} \mathrm{His}$; Kardailsky et al., 1999) or premature termination in $f t-7$ (Trp ${ }_{138}$ STOP; Corbesier et al., 2007), led to late flowering. A knockout FT mutant $f t-10$ in which a T-DNA was inserted in the first intron was also late flowering (Yoo et al., 2005). Moreover, different Arabidopsis thaliana ecotypes flowered at a various time dependent on their environmental adaptability. Through quantitative trait locus (QTL) mapping of the recombinant inbred line populations, Schwartz et al. (2009) found that the QTL interval to a $6.7 \mathrm{~kb}$ region upstream of the FT coding sequence. Tissue-specific expression assays by dissecting the FT promoter activities also reveal that $F T$ transcription is under the control of CONSTANS, and this occurs only in leaf veins but not the shoot meristem (Adrian et al., 2010). The FT transcript level increases under long-day (LD) but decreases under the short-day (SD), consistent with that Arabidopsis plants flowered much earlier in LD than SD growth conditions (Corbesier et al., 2007). It is believed that florigenic FT once expressed in leaves travels long distances to SAM to induce flowering. This is consistent with the compelling evidence for the requirement of the movement of FT in the induction of flowering (Abe et al., 2005; Wigge et al., 2005; Jaeger and Wigge, 2007; Mathieu et al., 2007). Taken together, these genetic and molecular analyses have demonstrated the role of FT and the requirement of movement of florigen in floral induction in plants.

\section{THE DEBATE ON THE NATURE OF MOBILE FLORIGEN: FLOWERING LOCUS T MRNA VERSUS FT PROTEIN}

Transcription of FT produces mRNA that then translates into the FT protein in leaves. It is no doubt that the FT protein is essential for cell-autonomous function in induction of flowering when it presents in SAM. However, the burning question is whether the FT protein or the FT mRNA is non-cell autonomous and directly contributes to the mobile florigenic signal. It is worthwhile noting that both protein and RNA (even DNA) can spread from cell to cell and over long-distance in plants. For instance, plant RNA and DNA viruses are long known to move their RNA and DNA genomes intercellular and systemically. Moreover, viruses express movement proteins that are required to promote the intercellular and systemic spread of viral RNA or DNA in plants (Qin et al., 2015). Thus, it is reasonable to presume that FT mRNA, its protein product, or both can contribute to florigen. Nevertheless, the initial finding that the FT mRNA produced under a heat shock-inducible promoter in distal leaf tissues can trigger flowering in SAM, attributing the FT mRNA as the non-cell autonomous mobile florigenic signal (Huang et al., 2005; Hurtley and Szuromi, 2005). However, this work cannot exclude the possibility of the potential role of the FT protein in the non-cell autonomous mobile florigenic signaling. Even more unfortunately, key data to support FT mRNA mobility were brought into question and this work has been retracted although heat treatment of local leaf was sufficient to induce flowering (Böhlenius et al., 2007).

In the meanwhile, the FT protein was reported to move long-distance and induce flowering in plants. For example, in LD Arabidopsis the FT-GFP fusion protein was shown to move across the grafting junction (Corbesier et al., 2007). On the other hand, in SD rice, $\mathrm{Hd} 3 \mathrm{a}$, the rice ortholog of Arabidopsis $F T$, is expressed in blade tissue, but interacts with SAM-specific FD, heralding that the FT protein spreads to SAM through vascular tissue (Tamaki et al., 2007). Recently, FT protein has been found to move from companion cells to sieve elements (Liu et al., 2020). However, whether FD is strictly SAM-specific is questionable since FD expression can also be detected in mature leaf tissues (Klepikova et al., 2016). This experiment suggests that it remains possible for both FT and FD RNAs to move to and then be translated into proteins in SAM (Pennisi, 2007). Thus, the nature of mobile florigen, FT mRNA vs FT protein, remains debatable.

\section{THE EVIDENCE ON MOBILE FLOWERING LOCUS T MRNA: TO MOVE OR NOT TO MOVE}

\section{Virus-Based RNA Mobility Assay}

As aforementioned, plant viruses can move their RNA and DNA genomes from cell to cell and over a long distance. This is determined (at least in part) by virus-encoded movement proteins. Thus, defects in viral movement proteins can rid viruses 
of intercellular and systemic mobility whilst such movementdeficient viruses can still replicate in single infected cells. Based on these, two plant RNA viruses, i.e., Potato virus $X$ (PVX, Chapman et al., 1992) and Turnip crinkle virus (TCV; Ryabov et al., 2004), were modified as RNA mobility Assay (RMA) vectors in which the coat protein gene was deleted from each virus genome. The resultant virus-based RMA vectors $\mathrm{PVX} / \triangle \mathrm{CP}$ and $\mathrm{TCV} / \triangle \mathrm{CP}$, can infect, but are restricted within individual leaf epidermal cells ( $\mathrm{Li}$ et al., 2009). By engineering the FT RNA into the two RMA vectors, it restores cell-tocell and long-distance movement of PVX/ $\triangle \mathrm{CP}$ and TCV/ $\triangle \mathrm{CP}$ RNA. Such virus-based RMAs provide compelling answers to three questions on FT mRNA movement. Firstly, FT mRNA can move long distances independent of FT protein. This conclusion was also confirmed by virus-free RMA in which FT RNA produced via agro-infiltration of local leaf tissues can spread to distal non-infiltrated newly growing leaves (Li et al., 2009). Secondly, the core mobile determinant consists of 102-nucleotides at the $5^{\prime}$ end of the FT mRNA (Li et al., 2009). Thirdly, FT $m R N A$ can facilitate PVX entry of SAM where viruses are usually excluded ( $\mathrm{Wu}$ et al., 2020), and leads to virus-induced gene silencing in SAM. Moreover, the long-distance FT RNA movement is also shown to enhance early flowering ( $\mathrm{Li}$ et al., 2011). It is worthwhile noting that the virus-based RMA is also used to show that long-distance movement of the BEL5 mRNA contributes to tuberization in potato (Cho et al., 2016).

\section{Grafting Evidence}

Grafting is one of the gold standard methods to study longdistance RNA movement (Gaut et al., 2019). Using heterografting technique coupled with RNAseq, 2,006 genes producing mobile mRNAs were identified in two different $A$. thaliana ecotypes (Thieme et al., 2015), and 138 Arabidopsis mobile mRNAs were found in A. thaliana (as stock) - Nicotiana benthamiana (as scion) system (Notaguchi et al., 2015). However, it is conceivable that this method is more suitable to identify mobile RNAs of high abundance. Therefore, it is unsurprising that FT mRNA with limited and dynamic expression pattern cannot be easily detected in previous studies (Corbesier et al., 2007; Tamaki et al., 2007). To avoid this issue, some mature leaves of the $\mathrm{ft}$-3 scion grafted onto the wild-type stock were removed in order to enrich potential wild-type FT mRNAs originated from wild-type stock. This indeed allows a positive detection of the wild-type FT mRNA movement from stock to scion through grafting junction (Lu et al., 2012). Furthermore, such grafting experiment also led to identify the 210-nt sequence at the $5^{\prime}$ end of FT mRNA as the mobility determinant ( $\mathrm{Lu}$ et al., 2012), consistent with the virus-based RMA's findings (Li et al., 2009).

\section{Intracellular RNA Imaging}

The bacteriophage coat protein MS2 can bind its target RNAs "stem-loop repeats (SL)." The MS2-GFP fusion protein is often used to label and image RNAs in different organisms (Querido and Chartrand, 2008). However, due to its high background fluorescent noise in the cytoplasm, this method is not extensively used in plants. Nevertheless, MS2 was found to be very specific nucleus localized when it is fused with transcription factor FD (Luo et al., 2018). The nuclear retention of MS2FD-GFP was much longer than $\mathrm{MS}_{\mathrm{SV}} 40_{-}-\mathrm{GFP}$. Luo et al. (2018) then coexpressed the MS2 $2_{\mathrm{FD}}-\mathrm{GFP}$, and chimeric SL-FT mRNA. Through fluorescent imaging, the $S L-F T$ mRNA was found to move intracellularly and mainly accumulated at the plasmodesmata sites; however, the dynamic process of the SL-FT mRNA moving from one cell to another was not observed (Luo et al., 2018).

\section{Mobile Flowering Locus $T$ mRNA-Assisted Seed Transmission of Gene Editing - Biotechnological Potential}

Clustered regularly interspaced short palindromic repeats (CRISPR)/CRISPR-associated protein 9 (CRISRP/Cas9) gene editing system has revolutionized targeted gene editing (Jinek et al., 2012; Cong et al., 2013; Feng et al., 2013). This gene editing tool contains three main components, Cas9 enzyme, spacer sequence and sgRNA (Jinek et al., 2012). Spacer and sgRNA are usually taken as a whole. As for plants, agrobacteriummediated CRISPR/Cas9 technology is widely used. However, this technology is often involved in genetically modified plants and time-consuming screen of homologous lines with the edited target gene. These issues can be partially avoided by a technology so called virus-induced gene/genome editing (ViGE; Ali et al., 2015).

However, gene editing resulted from ViGE is often not heritable to next-generation due to virus exclusion from SAM, thus its use is limited (Zhang et al., 2020). How to generate heritable ViGE is the issue that needs to be resolved. Recently, Ellison et al. (2020) have elegantly exploited the fact that the mobile translatable and non-translatable FT RNA can facilitate RNA virus entering SAM (Li et al., 2011), and used the Tobacco rattle virus (TRV) to deliver sgRNA-tagged with the mobile FT RNA into SAM. In the way, the mutant progeny of Nicotiana benthamiana were recovered in next-generation at frequencies ranging from 65 to $100 \%$; and due to sgRNA-targeting of PDS gene, the transgenerational seedlings with albino phenotype resulted from the PDS gene editing via TRV/(m)FT-sgRNA were statistically different compared with the mock control (Ellison et al., 2020). This demonstrated that the mobile FT RNA can promote the PDS sgRNA into SAM and enhances the progeny gene editing efficiency of the CRISPR/Cas9 system (Ellison et al., 2020). Similar results have been also reported using PVX to deliver FT RNA-tagged sgRNA to plants (Uranga et al., 2021).

Moreover, a cotton leaf crumple virus (CLCrV)-mediated $\mathrm{ViGE}$ system was also developed. In this case, sgRNAs were fused to the 102-nt FT mRNA, then expressed by CLCrV in transgenic Cas9 A. thaliana. The enhanced gene editing efficiency of 4.35$8.79 \%$ was found in progeny plants free of the CLCrV genome (Lei et al., 2021). Together, all these latest evidence shows that FT RNA is mobile and can enter SAM, as well as that such mobile RNA element has a high potential of biotechnological application in inheritable and transgenerational genome editing in plants and crops. 


\section{Movement of Flowering Locus T Homolog Genes}

Flowering Locus $T$ is one of six phosphatidyl ethanolaminebinding protein (PEBP) family members and the other five are TERMINAL FLOWER1 (TFL1) LIKE, MOTHER OF FT AND TFL1 (MFT), BROTHER OF FT AND TFL1 (BFT), ARABIDOPSIS THALIANA CENTRORADIALIS (ATC), and TWIN SISTER OF FT (TSF) in Arabidopsis (Karlgren et al., 2011). Phylogenetic analysis indicates that this small multigene family consists of three classes, FT-LIKE (FT and TSF), MFT, and TFL1-LIKE (ATC, BFT, and TFL1) (Chardon and Damerval, 2005). FT and TFL1 are two highly conserved homologous proteins, which have opposite functions but compete to regulate the initiation of plant flowering (Hanzawa et al., 2005). So far, there is no evidence that TFL1 RNA can move long distance. On the other hand, CET1 mRNA, an ortholog of the Arabidopsis antiflorigen $A T C$, is mobile, as revealed in tobacco/Arabidopsis grafting experiments. Its non-cell-autonomously movement is also confirmed in heterograft of tobacco and tomato (Huang et al., 2018). Other FT ortholog gene mRNAs were also found moving across the tomato-tobacco heterograft junction (Huang et al., 2018).

\section{WHAT DETERMINES THE MOBILITY OF FLOWERING LOCUS T MRNA?}

\section{Primary Flowering Locus T RNA Structures}

Synonymous codon substitution in FT (synFT) does not change the FT protein amino acid sequence but alters the RNA sequence. Notaguchi et al. (2008) transformed $f t-1$ with an expression cassette in which synFT contains 171 (of 175) codon substitutions. In grafting experiments where $f t-1$ was used as a recipient stock and transgenic synFT/ft-1 as a donor scion, the synFT $m R N A$ was not detectable in the $f t-1$ shoot apical region. These experiments also suggest that changes in the FT RNA sequence did not affect the FT protein movement (Notaguchi et al., 2008). However, unlike the later grafting study ( $\mathrm{Lu}$ et al., 2012), no enrichment of potential mobile synFT mRNA was done. This may explain why the synFT RNA could not be detected (Notaguchi et al., 2008). On the other hand, changes of primary mRNA sequence may lead to alternation of secondary structures (see below), which may be required for systemic FT RNA movement.

\section{RNA Secondary Structures}

A high number of tRNAs were detected in the phloem sap of pumpkin (Cucurbita maxima). Among these mobile tRNAs, their distributions are uneven. For example, no Ile-tRNA or very few Arg-tRNA but a few Asp-tRNA molecules were detected; however, Cys, Leu, Phe, Try, Trp, and Ser tRNAs were predominantly present in the phloem sap (Zhang et al., 2009). These tRNAs have been predicted to serve as longdistance signals (Zhang et al., 2009, 2016; Lezzhov et al., 2019; Wang et al., 2021), suggesting that tRNA or tRNA-like structure could be an important factor, if not the determinant for systemic RNA movement. Indeed, in the ViGE systems, like the $F T$ mRNA/102 nt-FT RNA element, Met, Gly, and Ile tRNAs were also found to improve transgenerational gene editing when they were fused to sgRNA (Ellison et al., 2020). It is possible that the FT mRNA may form unique structure, or tRNA/tRNA-like secondary or even tertiary structures that are important for its mobility.

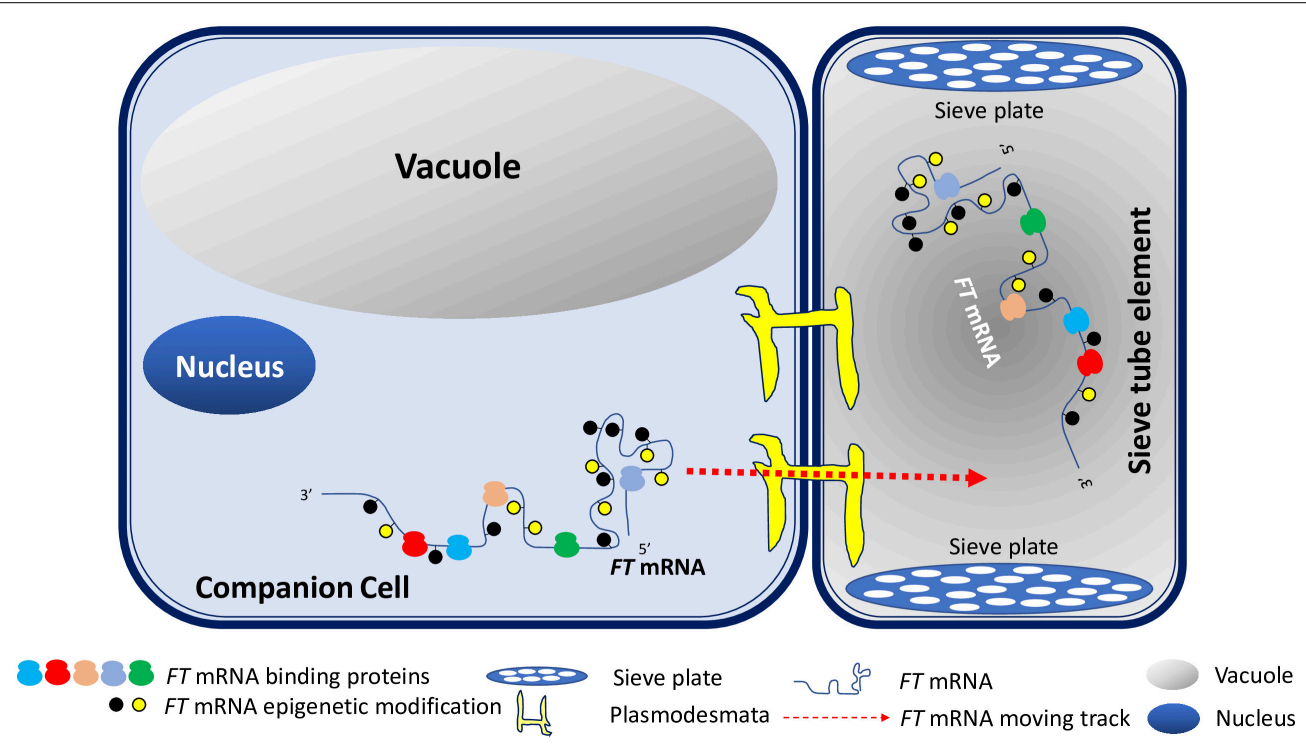

FIGURE 1 | A Model for FT mRNA Signaling. In companion cells, FT mRNAs may be epigenetically modified and form specific structures such as tRNA-like secondary structures. Such structured RNAs may then be recognized by RNA-binding proteins and transported through plasmodesmata into sieve tube. FT mRNAs will travel pass sieve plates through phloem to germline cells in shoot apical meristem to induce flowering along with other floral induction factors. 


\section{RNA Binding Proteins}

In plants, it is well-established that the movement of RNA requires RNA binding proteins. For example, KNOTTED1 (KN1) (Lucas et al., 1995) and a viral movement paralog protein in Cucurbita maxima, CmPP16 have been reported to be involved in cellular RNA trafficking (Xoconostle-Cázares et al., 1999). In Arabidopsis, a conserved SMALL RNA-BINDING PROTEIN 1 (SRBP1) family member, AtSRBP1, was found to mediate small RNA movement. AtSRBP1, a glycine-rich (GR) RNAbinding protein, also named AtGRP7, can bind to singlestranded siRNA (Yan et al., 2020). It is plausible that FT mRNA movement may also involve certain RNA binding protein(s) (Jackson and Hong, 2012).

\section{RNA Epigenetic Modification}

Numerous RNA modifications have been reported (Boccaletto et al., 2018) and some specific modifications are closely associated with biological functions (Chmielowska-Bąk et al., 2019). In plants, mRNA N6-methyladenosine $\left(\mathrm{m}^{6} \mathrm{~A}\right)$ and 5methylcytosine $\left(\mathrm{m}^{5} \mathrm{C}\right)$ play crucial and dynamic roles in embryo development, leaf morphogenesis, and root development (Liang et al., 2020). Recently, epigenetic modifications such as $\mathrm{m}^{5} \mathrm{C}$ have been found to be linked with RNA mobility and $\mathrm{m}^{5} \mathrm{C}$ RNAs are predominant in the phloem (Yang et al., 2019; Wang et al., 2021). Interestingly, in RNA $\mathrm{m}^{5} \mathrm{C}$ methylation-deficient mutants, mobile TRANSLATIONALLY CONTROLLED TUMOR PROTEIN 1 and HEAT SHOCK COGNATE PROTEIN 70.1 mRNAs become immobile (Yang et al., 2019). We speculate that $\mathrm{m}^{5} \mathrm{C}$ or other types of epigenetic modifications may play a role in FT mRNA mobility.

\section{PROSPECTIVE}

Specificized xylem and phloem are two conduits of the plant transportation system. They not only provide physical support for plants, but also are crucial to transport nutrients, minerals, and various signaling molecules in plants (De Rybel et al., 2016). Phloem consists of two types of cells: companion cells and sieve tubes. Sieve tubes lack nuclei. Almost all inorganic and organic substances are transferred from companion cells to sieve tubes via plasmodesmata (Slewinski et al., 2013). While local FT protein produced in source leaf tissues moves into SAM via the phloem-transportation highway, emerging evidence demonstrates that FT RNA can also undergo the same voyage en route to SAM. Therefore, it is possible that both FT mRNA and FT protein contribute to the florigen signal. Based on recent findings on the relevance of epigenetic RNA modifications,

\section{REFERENCES}

Abe, M., Kobayashi, Y., Yamamoto, S., Daimon, Y., Yamaguchi, A., Ikeda, Y., et al. (2005). FD, a bZIP protein mediating signals from the floral pathway integrator FT at the shoot apex. Science 12, 1052-1056. doi: 10.1126/science.1115983

Adrian, J., Farrona, S., Reimer, J. J., Albani, M. C., Coupland, G., and Turck, F. (2010). Cis-Regulatory elements and chromatin state coordinately control primary ribonucleotide sequences, secondary structures, and RNA binding proteins to RNA mobility, we propose a model for FT mRNA signaling in flowering (Figure 1). Once FT mRNAs is produced in companion cells, FT mRNAs may be epigenetically modified and form specific structures such as tRNA-like structures. Structured FT RNAs may then be recognized by RNA-binding proteins and transported through plasmodesmata into sieve tube. Along with the FT protein, FT mRNAs will move across sieve plates through phloem to germline cells in shoot apical meristem to induce flowering together with other floral induction factors. This model explains the possible movement of FT mRNA from specific companion cells to sieve tubes, then to distal SAM where they coordinate with other flowering induction factors to induce flowering (Figure 1). This model is also expected to be universal for the study of the mechanism of mobile mRNA in plants.

\section{AUTHOR CONTRIBUTIONS}

$\mathrm{ZY}$ and WC conceived the idea and wrote the draft of the manuscript. YH revised and finalized the manuscript. YW, PZ, and NS were involved in the discussion and helped to wrote the manuscript. All authors contributed to the article and approved the submitted version.

\section{FUNDING}

This work was in part supported by grants from Ministry of Science and Technology of China (National Key R\&D Program 2017YFE0110900), Ministry of Agriculture of the People's Republic of China (National Transgenic Program of China 2016ZX08009001-004); National Natural Science Foundation of China (31200913 and 31872636); Zhejiang Provincial Natural Science Foundation (LY19C020002), China Scholarship Council (201709645003), the Entrepreneurship and Innovation Project for the Overseas Returnees (or Teams) in Hangzhou (4105C5062000611), and Hangzhou Normal University (Sino-EU Plant RNA Signaling S\&T Platform Initiative 9995C5021841101).

\section{ACKNOWLEDGMENTS}

We thank colleagues in the Research Center for Plant RNA Signaling for constructive discussion and contributions to this manuscript. Due to constraints of mini-review, we apologize to colleagues whose work was not cited in this article.

temporal and spatial expression of Flowering Locus T in Arabidopsis. Plant Cell 22, 1425-1440. doi: 10.1105/tpc.110.074682

Ali, Z., Abul-faraj, A., Li, L. X., Ghosh, N., Piatek, M., Mahjoub, A., et al. (2015). Efficient virus-mediated genome editing in plants using the CRISPR/Cas9 system. Mol. Plant 8, 1288-1291. doi: 10.1016/j.molp.2015.02.011

Andrés, F., and Coupland, G. (2012). The genetic basis of flowering responses to seasonal cues. Nat. Rev. Genet. 13, 627-639. doi: 10.1038/nrg3291 
Boccaletto, P., Machnicka, M. A., Purta, E., Piątkowski, P., Bagiński, B., Wirecki, T. K., et al. (2018). MODOMICS: a database of RNA modification pathways. Nucleic Acids Res. 46, D303-D307. doi: 10.1093/nar/gkx1030

Böhlenius, H., Eriksson, S., Parcy, F., and Nilsson, O. (2007). Retraction. Science 316:367. doi: 10.1126/science.316.5823.367b

Borlaug, N. E. (2002). Feeding a World of 10 Billion people: the miracle ahead. In Vitro Cell. Dev. Biol. Plant 38, 221-228.

Chailakhyan, M. K. (1968). Internal factors of plant flowering. Annu. Rev. Plant Physiol. 19, 1-37. doi: 10.1146/annurev.pp.19.060168.000245

Chapman, S., Kavanagh, T., and Baulcombe, D. (1992). Potato virus X as a vector for gene expression in plants. Plant J. 2, 549-557. doi: 10.1046/j.1365-313x. 1992.t01-24-00999.x

Chardon, F., and Damerval, C. (2005). Phylogenomic analysis of the PEBP gene family in cereals. J. Mol. Evol. 61, 579-590. doi: 10.1007/s00239-004-0179-4

Chmielowska-Bąk, J., Arasimowicz-Jelonek, M., and Deckert, J. (2019). In search of the mRNA modification landscape in plants. BMC Plant Biol. 19:421. doi: 10.1186/s12870-019-2033-2

Cho, S. K., Sharma, P., Butler, N. M., Kang, I. H., Shah, S., Rao, A. G., et al. (2016). Polypyrimidine tract-binding proteins of potato mediate tuberization through an interaction with StBEL5 RNA. J. Exp. Bot. 66, 6835-6847. doi: 10.1093/jxb/erv389

Cong, L., Ran, F. A., Cox, D., Lin, S., Barretto, R., Habib, N., et al. (2013). Multiplex genome engineering using CRISPR/Cas systems. Science 339, 819-823. doi: $10.1126 /$ science. 1231143

Corbesier, L., Vincent, C., Jang, S., Fornara, F., Fan, Q., Searle, I., et al. (2007). FT protein movement contributes to long-distance signaling in floral induction of Arabidopsis. Science 316, 1030-1033. doi: 10.1126/science.1141752

De Rybel, B., Mähönen, A. P., Helariutta, Y., and Weijers, D. (2016). Plant vascular development: from early specification to differentiation. Nat. Rev. Mol. Cell Biol. 17, 30-40. doi: 10.1038/nrm.2015.6

Deeken, R., Ache, P., Kajahn, I., Klinkenberg, J., Bringmann, G., and Hedrich, R. (2008). Identification of Arabidopsis thaliana phloem RNAs provides a search criterion for phloem-based transcripts hidden in complex datasets of microarray experiments. Plant J. 55, 746-759. doi: 10.1111/j.1365-313X.2008. 03555.x

Ellison, E. E., Nagalakshmi, U., Gamo, M. E., Huang, P. J., Dinesh-Kumar, S., and Voytas, D. F. (2020). Multiplexed heritable gene editing using RNA viruses and mobile single guide RNAs. Nat. Plants 6, 620-624. doi: 10.1038/s41477-0200670-y

Evans, L. T. (1971). Flower induction and the florigen concept. Annu. Rev. Plant Physiol. 22, 365-394. doi: 10.1186/1472-6750-11-36

Feng, Z. Y., Zhang, B. T., Ding, W. N., Liu, X. D., Yang, D. L., Wei, P. L., et al. (2013). Efficient genome editing in plants using a CRISPR/Cas system. Cell Res. 23, 1229-1232. doi: 10.1038/cr.2013.114

Gaut, B. S., Miller, A. J., and Seymour, D. K. (2019). Living with two genomes: grafting and its implications for plant genome-to-genome interactions, phenotypic variation, and evolution. Annu. Rev. Genet. 53, 195-215. doi: 10. 1146/annurev-genet-112618-043545

Hanzawa, Y., Money, T., and Bradley, D. (2005). A single amino acid converts a repressor to an activator of flowering. Proc. Natl. Acad. Sci. U.S.A. 102, 7748-7753. doi: 10.1073/pnas.0500932102

Huang, N. C., Luo, K. R., and Yu, T. S. (2018). Mobility of antiflorigen and PEBP mRNAs in tomato-tobacco heterografts. Plant Physiol. 178, 783-794. doi: $10.1104 /$ pp.18.00725

Huang, T., Böhlenius, H., Eriksson, S., Parcy, F., and Nilsson, O. (2005). The mRNA of the Arabidopsis gene FT moves from leaf to shoot apex and induces flowering. Science 309, 1694-1696. doi: 10.1126/science.1117768

Hurtley, S., and Szuromi, P. (2005). The message is the messenger. Science 309:1647. doi: 10.1126/science.2005.309.5741.twis

Imaizumi, T., and Kay, S. A. (2006). Photoperiodic control of flowering: not only by coincidence. Trends Plant Sci. 11, 550-558. doi: 10.1016/j.tplants.2006.0 9.004

Jackson, S., and Hong, Y. (2012). Systemic movement of FT mRNA and a possible role in floral induction. Front. Plant Sci. 3:127. doi: 10.3389/fpls.2012. 00127

Jaeger, K. E., and Wigge, P. A. (2007). FT protein acts as a long-range signal in Arabidopsis. Curr. Biol. 17, 1050-1054. doi: 10.1016/j.cub.2007.05.008
Jinek, M., Chylinski, K., Fonfara, I., Hauer, M., Doudna, J. A., and Charpentier, E. (2012). A programmable dual-RNA-guided DNA endonuclease in adaptive bacterial immunity. Science 337, 816-821. doi: 10.1126/science.1225829

Kardailsky, I., Shukla, V. K., Ahn, J. H., Dagenais, N., Christensen, S. K., Nguyen, J. T., et al. (1999). Activation tagging of the floral inducer FT. Science 286, 1962-1965. doi: 10.1126/science.286.5446.1962

Karlgren, A., Gyllenstrand, N., Källman, T., Sundström, J. F., Moore, D., Lascoux, M., et al. (2011). Evolution of the PEBP gene family in plants: functional diversification in seed plant evolution. Plant Physiol. 156, 1967-1977. doi: 10. 1104/pp.111.176206

Klepikova, A. V., Kasianov, A. S., Gerasimov, E. S., Logacheva, M. D., and Penin, A. A. (2016). A high resolution map of the Arabidopsis thaliana developmental transcriptome based on RNA-seq profiling. Plant J. 88, 1058-1070. doi: 10.1111/ tpj. 13312

Lei, J. F., Dai, P. H., Li, Y., Zhang, W. Q., Zhou, G. T., Liu, C., et al. (2021). Heritable gene editing using FT mobile guide RNAs and DNA viruses. Plant Methods 17:20. doi: 10.1186/s13007-021-00719-4

Lezzhov, A. A., Atabekova, A. K., Tolstyko, E. A., Lazareva, E. A., and Solovyev, A. G. (2019). RNA phloem transport mediated by pre-miRNA and viral tRNAlike structures. Plant Sci. 284, 99-107. doi: 10.1016/j.plantsci.2019.04.005

Li, C., Gu, M., Shi, N., Zhang, H., Yang, X., Osman, T., et al. (2011). Mobile FT mRNA contributes to the systemic florigen signalling in floral induction. Sci. Rep. 1, 1-6. doi: 10.1038/srep00073

Li, C., Zhang, K., Zeng, X., Jackson, S., Zhou, Y., and Hong, Y. (2009). A cis element within Flowering Locus T mRNA determines its mobility and facilitates trafficking of heterologous viral RNA. J. Virol. 83, 3540-3548. doi: 10.1128/JVI. 02346-08

Liang, Z., Riaz, A., Chachar, S., Ding, Y. K., Du, H., and Gu, X. F. (2020). Epigenetic modifications of mRNA and DNA in plants. Mol. Plant 13, 14-30. doi: 10.1016/ j.molp.2019.12.007

Liu, L., Zhang, Y., and Yu, H. (2020). Florigen trafficking integrates photoperiod and temperature signals in Arabidopsis. J. Integr. Plant Biol. 62, 1385-1398. doi: 10.1111/jipb.13000

Lu, K. J., Huang, N. C., Liu, Y. S., Lu, C. A., and Yu, T. S. (2012). Longdistance movement of Arabidopsis FLOWERING LOCUS T RNA participates in systemic floral regulation. RNA Biol. 9, 653-662. doi: 10.4161/rna.19965

Lucas, W. J., Bouche-Pillon, S., Jackson, D. P., Nguyen, L., Baker, L., Ding, B., et al. (1995). Selective trafficking of KNOTTED1 homeodomain protein and its mRNA through plasmodesmata. Science 270, 1980-1983. doi: 10.1126/science. 270.5244.1980

Lucas, W. J., Groover, A., Lichtenberger, R., Furuta, K., Yadav, S. R., Helariutta, Y., et al. (2013). The plant vascular system: evolution, development and functions. J. Integr. Plant Biol. 55, 294-388. doi: 10.1111/jipb.12041

Luo, K. R., Huang, N. C., and Yu, T. S. (2018). Selective targeting of mobile mRNAs to plasmodesmata for cell-to-cell movement. Plant Physiol. 177, 604-614. doi: 10.1104/pp.18.00107

Mathieu, J., Warthmann, N., Küttner, F., and Schmid, M. (2007). Export of FT protein from phloem companion cells is sufficient for floral induction in Arabidopsis. Curr. Biol. 17, 1055-1060. doi: 10.1016/j.cub.2007.05.009

Notaguchi, M., Abe, M., Kimura, T., Daimon, Y., Kobayashi, T., Yamaguchi, A., et al. (2008). Long-distance, graft-transmissible action of Arabidopsis flowering locus T protein to promote flowering. Plant Cell Physiol. 49, 1645-1658. doi: $10.1093 / \mathrm{pcp} / \mathrm{pcn} 154$

Notaguchi, M., Higashiyama, T., and Suzuki, T. (2015). Identification of mRNAs that move over long distances using an RNA-Seq analysis of Arabidopsis/Nicotiana benthamiana heterografts. Plant Cell Physiol. 56, 311321. doi: $10.1093 / \mathrm{pcp} / \mathrm{pcu} 210$

Pennisi, E. (2007). Plant science. Long-sought plant flowering signal unmasked, again. Science 316, 350-351. doi: 10.1126/science.316.5823.350

Qin, C., Zhang, Q., He, M., Kong, J., Li, B., Mohamed, A., et al. (2015). Applied Plant Genomics and Biotechnology. Witney: Woodhead Publishing.

Querido, E., and Chartrand, P. (2008). Using fluorescent proteins to study mRNA trafficking in living cells. Methods Cell Biol. 85, 273-292. doi: 10.1016/S0091679X(08)85012-1

Ryabov, E. V., Van Wezel, R., Walsh, J., and Hong, Y. (2004). Cell-to-cell, but not long-distance, spread of RNA silencing that is induced in individual epidermal cells. J. Virol. 78, 3149-3154. doi: 10.1128/jvi.78.6.3149-3154.2004 
Schwartz, C., Balasubramanian, S., Warthmann, N., Michael, T. P., Lempe, J., Sureshkumar, S., et al. (2009). Cis-regulatory changes at FLOWERING LOCUS $\mathrm{T}$ mediate natural variation in flowering responses of Arabidopsis thaliana. Genetics 183, 723-732. doi: 10.1534/genetics.109.104984

Slewinski, T. L., Zhang, C., and Turgeon, R. (2013). Structural and functional heterogeneity in phloem loading and transport. Front. Plant Sci. 5:244. doi: 10.3389/fpls.2013.00244

Srikanth, A., and Schmid, M. (2011). Regulation of flowering time: all roads lead to Rome. Cell. Mol. Life Sci. 68, 2013-2037. doi: 10.1007/s00018-011-0673-y

Takahashi, F., and Shinozaki, K. (2019). Long-distance signaling in plant stress response. Curr. Opin. Plant Biol. 47, 106-111. doi: 10.1016/j.pbi.2018.1 0.006

Tamaki, S., Matsuo, S., Wong, H. L., Yokoi, S., and Shimamoto, K. (2007). Hd3a protein is a mobile flowering signal in rice. Science 316, 1033-1036. doi: 10. $1126 /$ science. 1141753

Thieme, C. J., Rojas-Triana, M., Stecyk, E., Schudoma, C., Zhang, W., Yang, L., et al. (2015). Endogenous Arabidopsis messenger RNAs transported to distant tissues. Nat. Plants 1, 1-9. doi: 10.1038/nplants.2015.25

Turck, F., Fornara, F., and Coupland, G. (2008). Regulation and identity of florigen: FLOWERING LOCUS T moves center stage. Annu. Rev. Plant Biol. 59, 573-594. doi: 10.1146/annurev.arplant.59.032607.092755

Uranga, M., Aragonés, V., Selma, S., Vázquez-Vilar, M., Orzáez, D., and Daròs, J. A. (2021). Efficient Cas9 multiplex editing using unspaced sgRNA arrays engineering in a Potato virus X vector. Plant J. 106, 555-565. doi: 10.1111/tpj. 15164

Wang, T., Li, X. J., Zhang, X. J., Wang, Q., Liu, W. Q., Lu, X. H., et al. (2021). RNA motifs and modification involve in RNA long-distance transport in plants. Front. Cell Dev. Biol. 9:651278. doi: 10.3389/fcell.2021.651278

Wigge, P. A., Kim, M. C., Jaeger, K. E., Busch, W., Schmid, M., Lohmann, J. U., et al. (2005). Integration of spatial and temporal information during floral induction in Arabidopsis. Science 309, 1056-1059. doi: 10.1126/science.111 4358

Wu, H., Qu, X., Dong, Z., Luo, L., Shao, C., Forner, J., et al. (2020). WUSCHEL triggers innate antiviral immunity in plant stem cells. Science 370, 227-231. doi: $10.1126 /$ science.abb7360

Xoconostle-Cázares, B., Xiang, Y., Ruiz-Medrano, R., Wang, H. L., Monzer, J., Yoo, B. C., et al. (1999). Plant paralog to viral movement protein that potentiates transport of mRNA into the phloem. Science 283, 94-98. doi: 10.1126/science. 283.5398 .94
Yan, Y., Ham, B. K., Chong, Y. H., Yeh, S. D., and Lucas, W. J. (2020). A plant small RNA-binding protein 1 family mediates cell-to-cell trafficking of RNAi signals. Mol Plant 13, 321-335. doi: 10.1016/j.molp.2019.12.001

Yang, L., Perrera, V., Saplaoura, E., Apelt, F., Bahin, M., Kramdi, A., et al. (2019). m5C methylation guides systemic transport of messenger RNA over graft junctions in plants. Curr. Biol. 29, 2465.e5-2476.e5. doi: 10.1016/j.cub.2019.0 6.042

Yanovsky, M. J., and Kay, S. A. (2003). Living by the calendar: how plants know when to flower. Nat. Rev. Mol. Cell Biol. 4, 265-276. doi: 10.1038/nrm 1077

Yoo, S. K., Chung, K. S., Kim, J., Lee, J. H., Hong, S. M., Yoo, S. J., et al. (2005). CONSTANS activates SUPPRESSOR OF OVEREXPRESSION OF CONSTANS 1 through FLOWERING LOCUS T to promote flowering in Arabidopsis. Plant Physiol. 139, 770-778. doi: 10.1104/pp.105.066928

Zhang, S. D., Sun, L., and Kragler, F. (2009). The phloem-delivered RNA pool contains small noncoding RNAs and interferes with translation. Plant Physiol. 150, 378-387. doi: 10.1104/pp.108.134767

Zhang, W. N., Thieme, C. J., Kollwig, G., Apelt, F., Yang, L., Winter, N., et al. (2016). tRNA-related sequences trigger systemic mRNA transport in plants. Plant Cell 28, 1237-1249. doi: 10.1105/tpc.15.01056

Zhang, X., Kang, L. H., Zhang, Q., Meng, Q. Q., Pan, Y. F., Yu, Z. M., et al. (2020). An RNAi suppressor activates in planta virus-mediated gene editing. Funct. Integr. Genomics 20, 471-477. doi: 10.1007/s10142-019-00730-y

Conflict of Interest: The authors declare that the research was conducted in the absence of any commercial or financial relationships that could be construed as a potential conflict of interest.

Publisher's Note: All claims expressed in this article are solely those of the authors and do not necessarily represent those of their affiliated organizations, or those of the publisher, the editors and the reviewers. Any product that may be evaluated in this article, or claim that may be made by its manufacturer, is not guaranteed or endorsed by the publisher.

Copyright (C) 2022 Yu, Chen, Wang, Zhang, Shi and Hong. This is an open-access article distributed under the terms of the Creative Commons Attribution License (CC BY). The use, distribution or reproduction in other forums is permitted, provided the original author(s) and the copyright owner(s) are credited and that the original publication in this journal is cited, in accordance with accepted academic practice. No use, distribution or reproduction is permitted which does not comply with these terms. 